\title{
Comparative Study of Prescribing Trends of Analgesics in Post Operative Pain Management in Surgery Units Between Government And Private Medical College Hospital
}

\author{
Mohammad Abdullah Al Masud', S M Niazur Rahman², Zaida Rahman ${ }^{3}$, Ruksana Amin ${ }^{4}$, \\ Syed Ashrafuzzaman ${ }^{5}$, Tanbira Alam ${ }^{6}$
}

\begin{abstract}
:
The study was done to compare the prescribing trend of analgesics used in post operative patients in surgery units of a government and a private medical college hospital of Dhaka city. A total of 360 prescriptions of patients who underwent surgery were collected randomly .Among 360 prescriptions, 180 were collected from the government and other from private medical college hospital from the period of July 2007 to June 2008. Data pertaining to medications prescribed for pain management from the day of operation to sixth post operative day were recorded. It was observed that in government medical college and hospital $90.6 \%$ patients received pethidine on the operation day. Other associated analgesics on that day were either tramadol $(42.2 \%)$ or ketorolac $(54.4 \%)$. Only $9.4 \%$ patients did not receive any analgesic on that day. In private medical college hospital $65.6 \%$ patients received nalbuphine and $33.3 \%$ patients received pethidine on the operation day. Along with nalbuphine and pethidine, $86.7 \%$ patients received tramadol and $13.3 \%$ patients received ketorolac. $0.6 \%$ patients did not receive any analgesic on that day. In government medical college hospital, most of the patients received only tramadol $(48.3 \%)$, ketorolac $(38.9 \%)$ and pethidine $(0.6 \%)$ on the first post operative day as a single drug. In private medical college hospital, $84.4 \%$ patients received ketorolac and $15.6 \%$ patients received tramadol on the $1^{\text {st }}$ post operative day. In government hospital most of the patients received tramadol whereas in private medical college hospital most of the patients received ketorolac on $2^{\text {nd }}, 3^{\text {rd }}, 4^{\text {th }}$ and $5^{\text {th }}$ post operative day. On $6^{\text {th }}$ post operative day, $81.1 \%$ patients did not receive any analgesic in government hospital and $92.8 \%$ patients did not receive any analgesic in private medical college hospital.
\end{abstract}

1. Assistant Professor, Department of Pharmacology \& therapeutics, Enam Medical College, Savar, Dhaka

2. Lecturer, Department of Physiology, Holy Family Red Crescent Medical College, Dhaka

3. Associate Professor Department of pharmacology \& Therapeutics, Enam Medical College, Savar, Dhaka.

4. Assisstant Professor, Department of pharmacology \& Therapeutics, Anwer Khan Modern Medical College

5. Ex Professor. Department of Pharmacology \& Therapeutics, Sir Salimullah Medical College, Dhaka

6. Lecturer, Dept. of Physiology, Holy Family Red Crescent Medical College, Dhaka

\section{Introduction:}

The goal for postoperative pain management is to reduce or eliminate pain and discomfort with a minimum of side effects as cheaply as possible ${ }^{1}$. Optimal post operative management is therefore mandatory to enable early mobilization and rehabilitation, to enhance recovery and to reduce morbidity ${ }^{2}$. 
Post operative pain management is an important but seemingly undervalued component of perioperative care. Over the past decade, medical societies, governmental agencies and accrediting bodies such as Joint Commission on Accreditation of Health care Organizations (JCAHO) have paid increasing attention to the management of all types of pain, including postoperative pain ${ }^{3}$.

Despite this increased focus, many patients continue to experience significant post operative pain. Inadequately controlled pain can cause post operative morbidity, prolong recovery time, delay return to normal living and decrease satisfaction with care. Inadequate pain management increases the use of health care resources, thereby increasing total health care costs ${ }^{4}$.

Opioid analgesics have long been shown to produce a dose-dependent reduction in the minimum alveolar concentration (MAC) of volatile anesthetics. However in animal studies designed to assess the effect of ketorolac on the volatile anesthetic requirement, no reduction in MAC could be demonstrated $^{6}$. Thus it is not surprising to find that per-operative anesthetic conditions are generally less satisfactory when ketorolac is used as an alternative to a potent opioid analgesic?

Despite the failure of Non Steroidal Anti Inflammatory Drugs (NSAIDs) to replace opioid analgesics in the management of acute per and post operative pain, these drugs may play a useful role as adjuvant for improving post operative analgesia. In a placebo controlled study involving ambulatory surgery patients, Ketorolac $30-60 \mathrm{mg}$ intravenous given per-operatively, produced a dosedependent decrease in post operative pain scores and opioid analgesic requirements ${ }^{\gamma}$. Post operative pain is one of the most prevalent acute type of pain and is an expected result of surgical procedures experienced by thousands of patients all over the world".

In developed countries, the interest in the economic aspects of analgesia applied during the post operative period is recent and has been concentrated on high cost treatments, especially in view of the use of new technologies in the management of discomfort'. In Bangladesh, no standard guideline is followed for post operative pain management. In view of the above considerations and scenario, an attempt was taken to compare the pattern of analgesics used in post operative patients in surgery units of a government and private medical college hospital to find out whether there is a significant difference between them.

\section{Materials and method:}

A cross sectional comparative study was conducted in a government and a private medical college hospital of Dhaka city. Prescriptions of a total of 360 patients who underwent surgery were collected randomly180 from the government and 180 from the private medical college hospital from the period of July 2007 to June 2008.

The treatment sheets given by the medical officers and specialist doctors to the patients undergoing surgery were included in the study. The prescriptions which did not contain analgesics were excluded and the prescriptions of the patients suffering from diabetes mellitus, hypertension and any cardiac diseases were also excluded. Statistical analysis of data were done using SPSS program version of 12.0 software. 


\section{Results:}

Data pertaining to pain medications prescribed from the day of operation to sixth post operative day were recorded.While comparing, It was observed that in Govt.medical college \& hospital $90.6 \%$ patients received pethidine in the operation day. Associated analgesics on that day were either tramadol $(42.2 \%)$ or ketorolac $(54.4 \%)$. $9.4 \%$ patients did not receive any analgesic on that day. In private medical college \& hospital $65.6 \%$ patients received nalbuphine and $33.3 \%$ patients received pethidine in the operation day. Along with nalbuphine and pethidine, $86.7 \%$ patients received tramadol and $13.3 \%$ patients received ketorolac. $0.6 \%$ patients did not receive any analgesic on that day. The difference of use of tramadol and ketorolac as associated medicine in the operation day were significantly different $(p<0.001)$ in these two hospiotals. In Govt. medical college hospital $48.3 \%$ patients received tramadol, $38.9 \%$ received ketorolac \& $0.6 \%$ received pethidine on the $1^{\text {st }}$ post operative day. In private medical college hospital, $84.4 \%$ patients received ketorolac and $15.6 \%$ patients received tramadol on the $1^{\text {st }}$ post operative day which is significantly different $(p<0.001)$ from the govt. hospital. In Govt medical college hospital most of the patients received tramadol on $2^{\text {nd }}, 3^{\text {ts }}, 4^{\text {th }}$ and $5^{\text {th }}$ post operative day. On the other hand, most patients received ketorolac in private medical college hospital on $2^{\text {nd }}, 3^{\text {rd }}, 4^{\text {th }}$ and $5^{\text {th }}$ post operative day. Private medical college hospital used more costly drug more frequently than govt. medical college hospital in the later post operative days but pain control did not differ significantly in these two hospitals. On $6^{\text {th }}$ post operative day, $81.1 \%$ patients did not receive any analgesic in government hospital and $92.8 \%$ patients did not receive any analgesic in private medical college hospital.

Table-I: Distribution of patients according to analgesics used from the operation day to the sixth post operative day:

\begin{tabular}{|c|c|c|c|c|c|c|c|c|c|c|c|c|}
\hline \multirow[t]{2}{*}{$\begin{array}{l}\text { Day of } \\
\text { operation }\end{array}$} & \multicolumn{2}{|c|}{$\begin{array}{c}\text { Pethidine } \\
(\mathrm{N}=180) ; \\
\mathrm{N}(\%)\end{array}$} & \multicolumn{2}{|c|}{$\begin{array}{l}\text { Nalbuphine } \\
N=180 ; N(\%)\end{array}$} & \multicolumn{2}{|c|}{$\begin{array}{c}\text { Tramadol } \\
N=180 ; N(\%)\end{array}$} & \multicolumn{2}{|c|}{$\begin{array}{c}\text { Ketorolac } \\
\mathrm{N}=180 ; \mathrm{N}(\%)\end{array}$} & \multicolumn{2}{|c|}{$\begin{array}{c}\text { Others } \\
\mathrm{N}=180 ; \mathrm{N}(\%)\end{array}$} & \multicolumn{2}{|c|}{$\begin{array}{c}\text { Not Used } \\
N=180 ; N(\%)\end{array}$} \\
\hline & $\begin{array}{c}\text { Govt. } \\
\text { medical }\end{array}$ & $\begin{array}{l}\text { Private } \\
\text { medical }\end{array}$ & $\begin{array}{c}\text { Govt. } \\
\text { medical }\end{array}$ & $\begin{array}{l}\begin{array}{c}\text { Private } \\
\text { medical }\end{array} \\
\end{array}$ & $\begin{array}{c}\text { Govt. } \\
\text { medical }\end{array}$ & $\begin{array}{l}\text { Private } \\
\text { medical }\end{array}$ & \begin{tabular}{|c|} 
Govt. \\
medical
\end{tabular} & $\begin{array}{c}\text { Private } \\
\text { medical }\end{array}$ & $\begin{array}{c}\text { Govt. } \\
\text { medical }\end{array}$ & $\begin{array}{l}\text { Private } \\
\text { medical }\end{array}$ & $\begin{array}{c}\text { Govt. } \\
\text { medical }\end{array}$ & $\begin{array}{l}\text { Private } \\
\text { medical }\end{array}$ \\
\hline $\begin{array}{l}\text { Operation } \\
\text { day }\end{array}$ & $163(90.6)$ & $61(33.9)$ & $\cdot$ & $118(65.6)$ & $76(42.2)$ & $156(86.7)$ & $98(54.4)$ & $24(13.3)$ & . & . & $17(9.4)$ & $1(0.6)$ \\
\hline $1^{\pi}$ POD & $1(0.6)$ & 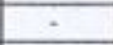 & $\cdot$ & $\cdot$ & $87(48.3)$ & $28(15.6)$ & $70(38.9)$ & $152(84.4)$ & $22(12.2)$ & 5 & $\cdot$ & $\cdot$ \\
\hline $2^{a}$ POD & $\cdot$ & $\div$ & $\div$ & $\cdot$ & $86(47,8)$ & $25(13.9)$ & $67(37.2)$ & $155(86.1)$ & $27(15)$ & $\cdot$ & $\cdot$ & 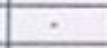 \\
\hline $3^{\mathrm{N}} \mathrm{POD}$ & - & $\cdot$ & $\cdot$ & $\cdot$ & $80(44.4)$ & $26(14.4)$ & $63(35)$ & $154(85.6)$ & $37(20.6)$ & $\cdot$ & $\cdot$ & $\cdot$ \\
\hline $4^{4}$ POD & 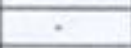 & - & $\cdot$ & $\cdot$ & $74(41.1)$ & $29(16.1)$ & $58(32.2)$ & $151(83.9)$ & $48(26.7)$ & - & . &. \\
\hline $5^{\mathrm{t}} \mathrm{POD}$ & $\cdot$ & $\cdot$ & $\cdot$ & $\cdot$ & $58(32.2)$ & $23(12.8)$ & $45(25)$ & $112(62.2)$ & $43(23.9)$ & $\cdot$ & & $45(25)$ \\
\hline $6^{\text {t1 }}$ POD & $\cdot$ & $\cdot$ & 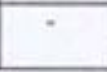 & $\cdot$ & $13(7.2)$ & $3(1.7)$ & $08(4,4)$ & $10(5.6)$ & $13(7.2)$ & 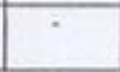 & & $67(92.8$ \\
\hline
\end{tabular}




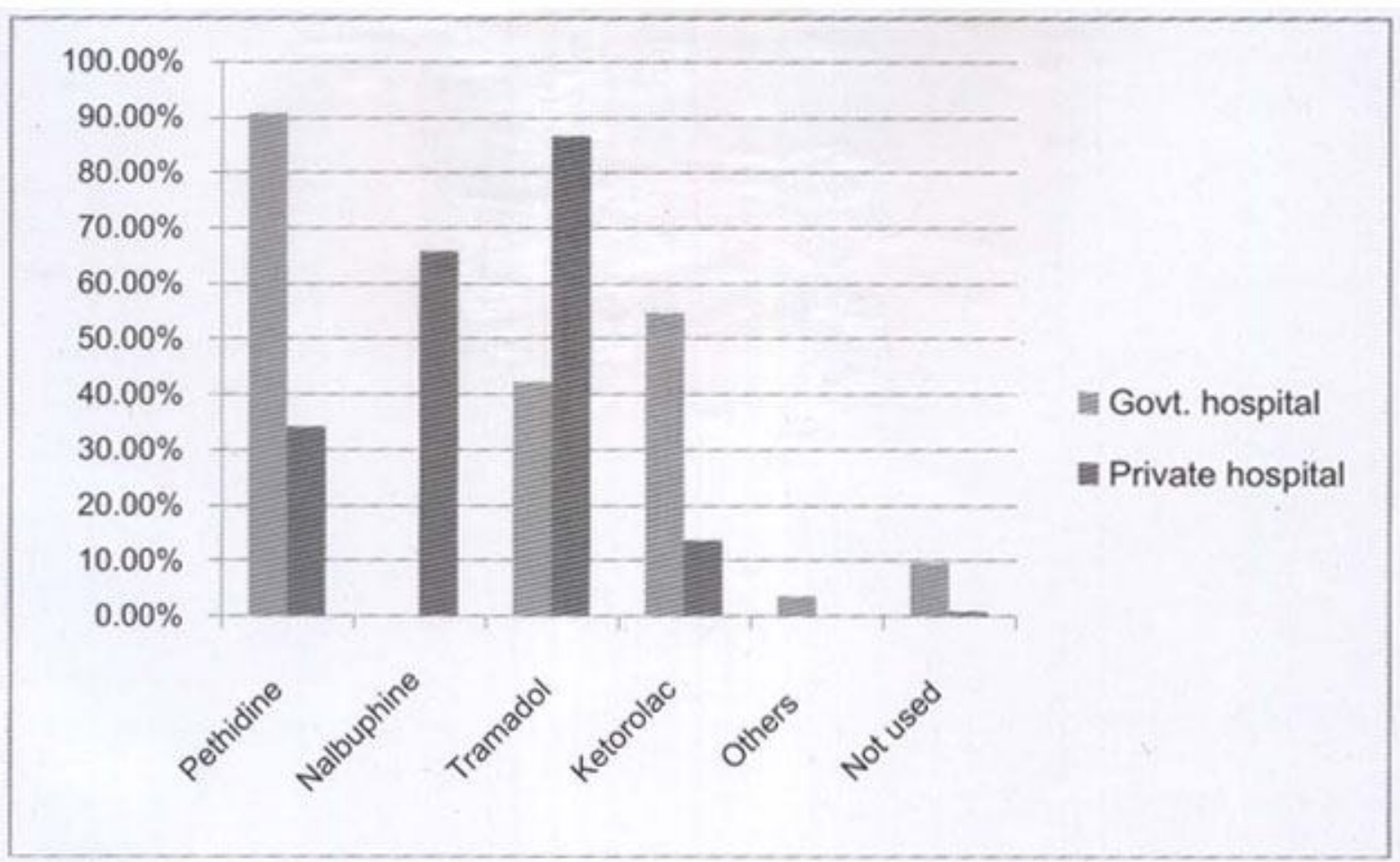

Figure 1: Distribution of patients admitted in two medical college hospitals according to analgesics used in the operation day

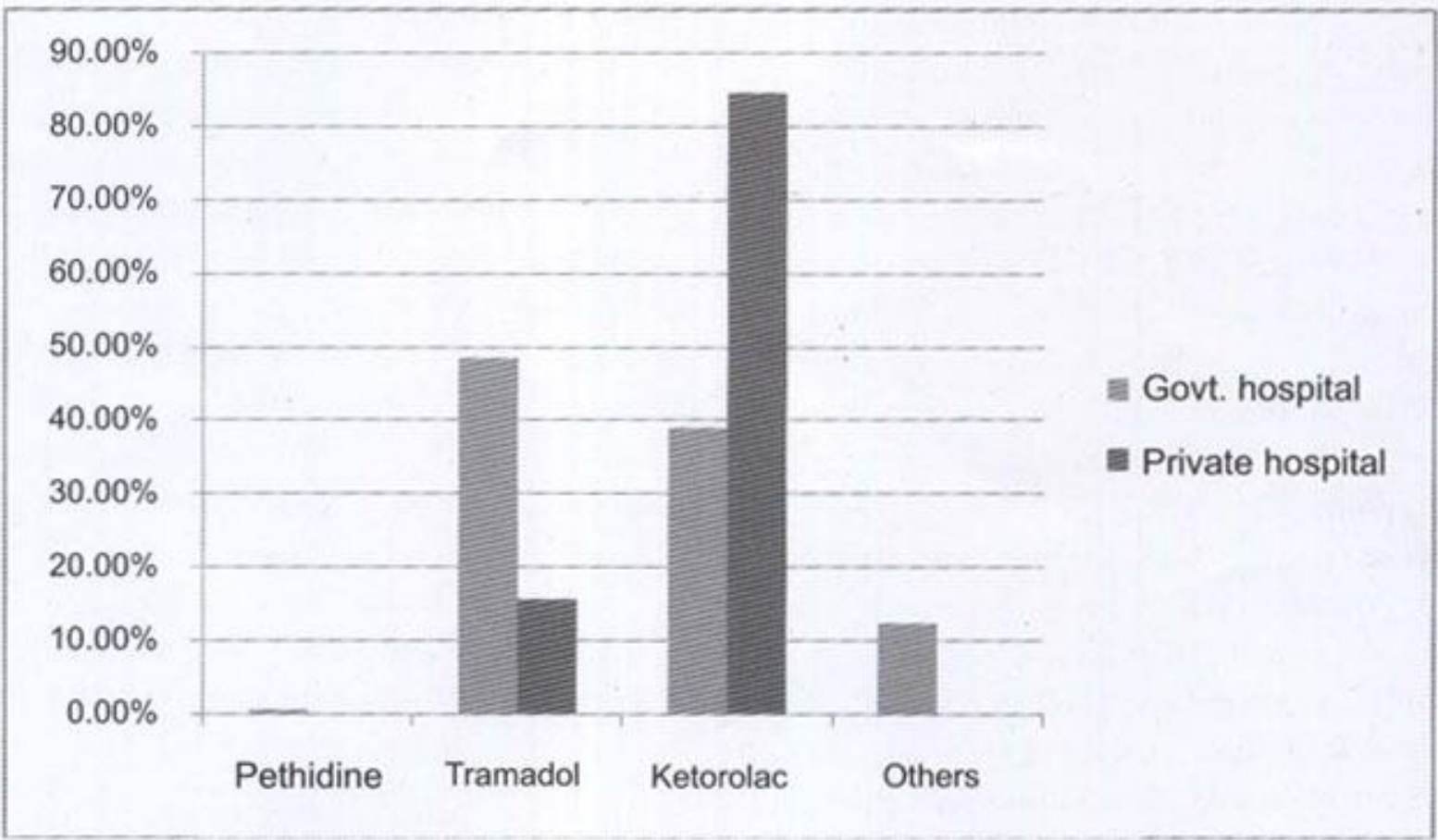

Figure 2: Distribution of patients admitted in two medical college hospitals according to analgesics used in the 1st post operative day 


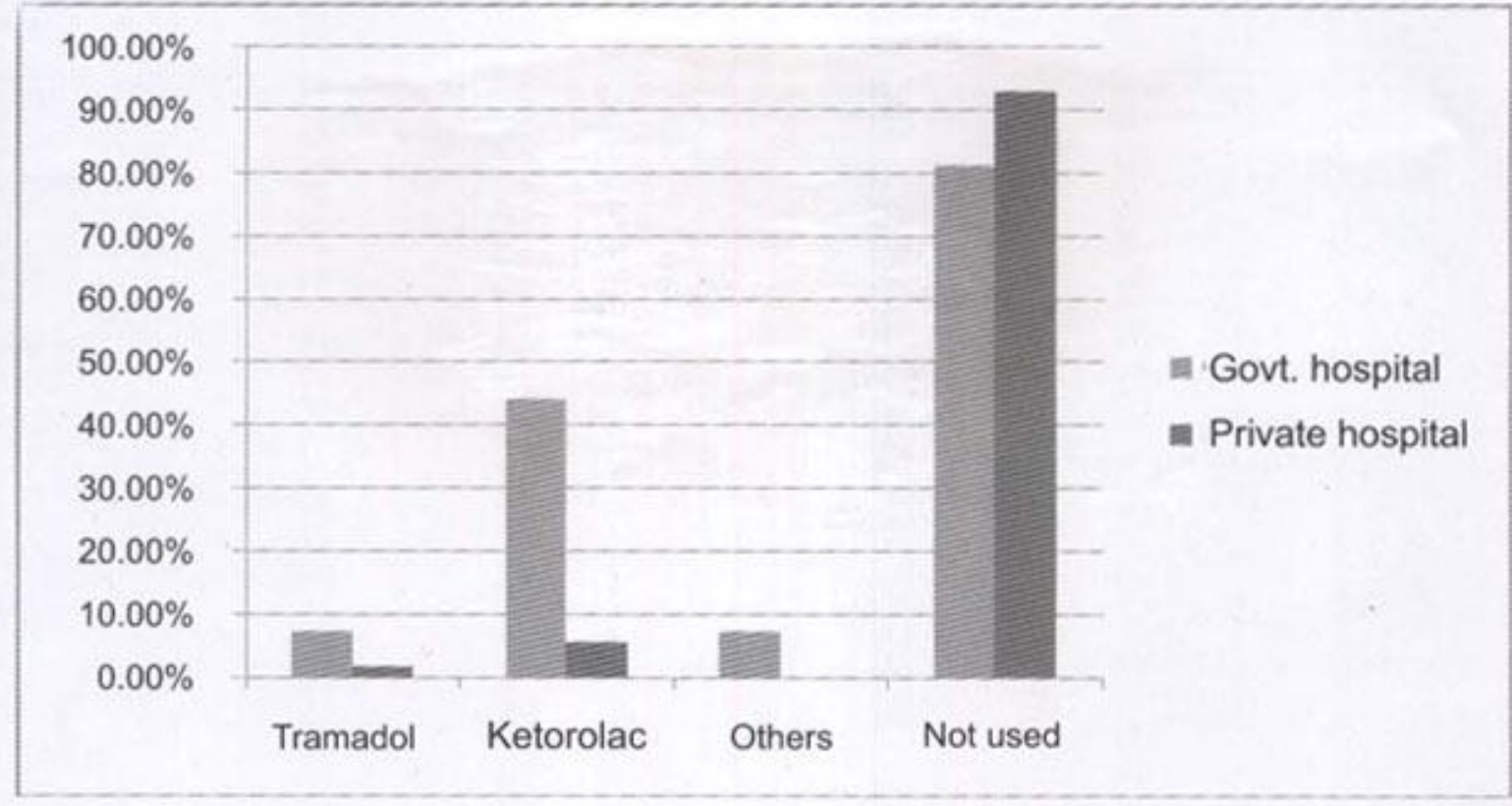

Figure 3: Distribution of patients admitted in two medical college hospitals according to analgesics used in the $6^{\text {th }}$ post operative day

\section{Discussion:}

The study was done to evaluate the prescribing trend of analgesics used in surgery in two selected medical college hospital, one government and one private medical college hospital of Dhaka city. Treatment sheets (prescriptions) of the patients after surgery were evaluated for analgesics used from the day of operation to $6^{\text {th }}$ post operative days. It was observed that pethidine was the most prescribed drug in the govt. medical college hospital while nalbuphine $(65.65 \%)$ was the most used drug in private medical college hospital in the operation day. Possibly nalbuphine was more used in private hospital because patient had to purchase pethidine from outside which was expensive than nalbuphine and difficult to obtain because pethidine is a regulated product. One previous study found that nalbuphine has a longer duration of action than pethidine while pain intensity and visual analogue scores were considered. It was also found that the respiration rate in the pethidine group were significantly more depressed than in nalbuphine group. Nalbuphine caused less depression of both systolic and diastolic blood pressure at both 30 and 60 minutes $^{10}$. Another study proposed that nalbuphine is a suitable alternative to pethidine, producing sedation which is maximum at $60 \mathrm{~min}$. after injection. However, they also reported nausea and vomiting of delayed onset as a disadvantage of nalbuphine ${ }^{11}$. Other associated analgesic in the operation day in Govt. medical college hospital was either tramadol $(42.2 \%)$ or ketorolac $(54.4 \%)$. In private medical college hospital most patients received tramadol $(86.7 \%)$ and few patients $(13.3 \%)$ received ketorolac in the operation day. The use of tramadol and ketorolac in the operation day was significantly different $(\mathrm{p}<0.001)$ in these two hospitals.

The private medical college hospital used less costly drug more frequently than the government medical college hospital in the 
operation day as associated medicine with pethidine or nalbuphine.

In govemment medical college hospital, $48.3 \%$ patients received tramadol and $38.9 \%$ patients received ketorolac on the first post operative day. On the other hand, in private medical college hospital $84.4 \%$ patients received ketorolac and $15.6 \%$ patients received tramadol on the first post operative day which was significantly different from that of the govt. hospital. Private medical college hospital used more costly drug than the government medical college hospital from first post operative day onwards. But the pain score did not differ significantly in these two hospitals in the later post operative days. Cause of use of more costly drugs by the private hospital may be due to drug promotion by pharmaceutical companies. One of the factors that influence prescription pattern of the doctors is drug promotion by the pharmaceutical companies. Promotion can be beneficial for society as a means of providing information but it can also be harmful in a sense that it lowers price sensitivity of the doctors and it merely is a means of establishing market share, even when cheaper, therapeutically equivalent drugs are available ${ }^{12}$.

The therapeutic value of a rational use of analgesics may not be questionable. However excessive exposure to analgesics poses potential adverse effects and also consumes considerable amount of drug budget ${ }^{13}$.

The difference in prescribing pattem between the government and private medical college hospital may be attributed to lack of definite guidelines, undue drug promotion by representative of pharmaceutical companies and easy availability of drugs (pethidine) in government medical college hospital.

Standard Treatment Guideline (STG) should be introduced to avoid discrepancy among the hospitals through out the country. It will help rational use of analgesics thereby reduce the unnecessary health expenditure with the introduction of safe and effective analgesics for post operative pain relief.

\section{References:}

1. Charlton Ed. The management of post operative pain. Anesth 1997; 7; 1-7.

2. Kehlet $H$. Acute pain control and accelerated post operative surgical recovery. Surg Clin North Am 1999; 79: 431-43.

3. Ritchey RM. Optimizing post operative pain management. Cleve Clin J Med 2006; 73: 72-76.

4. Joshi PG, Ogunnaike BO. Consequences of inadequate post operative pain relief and chronic persistent post operative pain. Anesthesiol Clin North Am 2005; 23: 21-36.

5. Hoffman JC, Di Fazio CA. The anesthesia sparing effect of pentazocine, meperidine and morphine. Arch Int Pharmacodyn Ther 1970; 18: 261-8.

6. Rich GF, Schacterie R, Moscicki JC, Di Fazio CA, Adams JM. Ketorolac does not decrease the MAC of halothane or depress ventilation in rats. Anesth Analg.1992; 75: 99-102.

7. Ding $Y$, White PF. Simplified quality of anesthesia scoring system. Anesthesia 1992; 47: 906-7.

8. Souter AJ, Fredman B, White PF. Controversies in the perioperative use of Nonsteroidal Anti-inflammatory drugs. Anesth Analg 1994: 79: 78-90. 
9. Ashburn MA, Ready LB. Post operative pain. In: Loeser JD, Bulter S, Chapman $\mathrm{CR}$, Turk DC (ed.). Bonica's management of pain. Philadelphia: Lippincott Williams and Wilkins. 2001; pp-765-79.

10. Yasin B, Asghar M. Nalbuphine compared to pethidine for post operative relief after orthopedic surgery. Anesth Pain Intens Care 2005; 9: 3-6.

11. Chestnutt WN, Clarke RSJ, Dundee JW. Comparison of Nalbuphine, Pethidine and placebo as premedication for minor Gynecological surgery. Br J Anesth 1987; 59: 576-580.
12. Windmeijer F, Laat Ed, Douven R, Mot E. "Pharmaceutical promotion and GP prescription behavior", CPB Nethehrlands Bureau for Economic Policy Analysis 2004.

13. Leka T, Abadir M. Prescribing pattern of analgesic drugs in 13 rural and regional hospitals of Ethiopia. Ethiop $\mathrm{J}$ Health. $1990 ; 4: 15-30$. 